\title{
Hydrogen Storage Using Ionic Liquid Media
}

\author{
Martin H. G. Prechtl ${ }^{1 *}$ and Sebastian Sahler ${ }^{1}$ \\ ${ }^{1}$ University of Cologne, Cologne, Germany
}

\begin{abstract}
The application of ionic liquids revealed a new dimension in many fields of chemistry. In the particular field of hydrogen storage system ionic liquids find application in several different ways. After a short introduction about the matter of hydrogen storage and its advantages and challenges, the different approaches of ionic liquid application in this field are presented. The different approaches can be classified into the application of ionic liquids as (i) solvent, as (ii) co-catalyst, as (iii) catalyst, as (iv) hydrogen storage material and as (v) stabilizing agent for nano particles. The benefit of ionic liquids for the system is discussed in this review.
\end{abstract}

Keywords: Ionic liquids, Hydrogen storage, Ammonia borane, Formic acid, Dehydrogenation, Catalysis.

\section{INTRODUCTION}

The majority of the world's transportation is based on limited resources of fossil oil as mobile energy medium. For the future, alternative materials for energy storage have to be found. An interesting material to overcome this problem is hydrogen gas [1-2]. Hydrogen has the advantages of low weight, thus, high energy density per kilogram, it is abundant in form of water and environmental benign as the combustion of hydrogen results in the formation of water. The drawbacks of molecular hydrogen are (i) the low density as gas, (ii) for the compression of gas the application of heavy pressure tanks is necessary and (iii) for cryogenic storage at low temperature in the liquid state efficient isolation is crucial [1, 3-6].

Alternatively to the storage in the molecular form, one can consider the storage of protic and hydridic hydrogen in organic or inorganic materials as a possibility to overcome the mentioned drawbacks. Such materials should contain reasonably high amounts of chemically bound hydrogen to compete with the physical storage of molecular dihydrogen. One of the highest hydrogen contents in weight percent $(\mathrm{wt} \%)$ can be found in the Lewis pair ammonia borane $(A B ;>19 w t \%)$. Ammonia borane $(A B)$ and its derivatives have been under investigation for hydrogen storage since several years. Moreover, simple compounds such as $\mathrm{CO}_{2}$ and its hydrogenation product formic acid (FA) are considered due to a decent content of hydrogen $(4.4 \mathrm{wt} \%)$ [7-10]. Ammonia borane is more efficient than elemental hydrogen regarding the energy density (energy/volume ratio), but $\mathrm{AB}$ bears problems concerning regeneration and transportation. The established infrastructure for the distribution of energy carriers is designed for liquid fuels, thus, a solid energy carrier like $\mathrm{AB}$ has some disadvantages competing with liquid fuels.

In summary, it seems more convenient to find a new liquid fuel system. In this regard, ionic liquids (ILs) have promising advantages due to their variable physico-chemical properties [11]. Currently research focuses on hydrogen-enriched inorganic and organic materials and on catalytic dehydrogenation as well as regeneration of waste by hydrogenation [12-16]. ILs are interesting due to their ability to act as promoting agent for the dehydrogenation and in

*Address correspondence to this author at the University of Cologne, Cologne, Germany; Tel: +49-221-4701981; Fax: +49-221-4701788;

E-mail: martin.precht1@uni-koeln.de certain cases to dissolve hydrogen carrier materials, as well as to solubilize specific spent fuel products [16-17]. In certain cases these properties are combined for application [16].

\subsection{Ionic Liquids}

Since the 1990s ILs changed from a "laboratory curiosity" to a very popular compound class in a broad range of research in natural science and especially in chemistry [18-24]. The physico-chemical properties of ILs - they are non-flammable, non-volatile, highly solvating, often weakly coordinating, have a tunable polarity and good thermal stability - make them attractive for a variety of applications $[11,25]$. The definition has been established that salts with a melting point below $100^{\circ} \mathrm{C}$ are classified as ILs [24, 26-27].

The remarkable low melting points for ionic compounds are related to the reduced lattice energy due to large ion-pairs and low symmetry of the cations (Fig. 1) $[11,25,28]$. ILs are known since 1913, however their predicted potential for wide spread application only developed rapidly in the last two decades. A historical introduction can be found in the overview by Wilkes [29].

Tailoring the ion structures gives access to the tuning of the properties of the ILs [30-34]. Thus, it is possible to design ILs with defined hydrophilicity or hydrophobicity, viscosity as well as coordinating properties. Moreover, the acidity or basicity of the whole reaction system is important, since ILs based on imidazolium cations contain a quite acidic proton in the $\mathrm{C}_{2}$-position [22, 24, 27, $35]$, therefore solvated metal species may form carbene complexes in certain cases [36]. This complexation can be suppressed by protection of the $\mathrm{C}_{2}$-position with a methyl group. ILs are commonly used to stabilize and immobilize homogeneous and heterogeneous catalysts against decomposition or agglomeration [22].

The yield of a reaction is strongly influenced by the solubility of reactants, intermediates and products. In the case of hydrogen generation by dehydrogenation reactions, the driving force to push the equilibrium to the product side is based on the rather low solubility of gaseous hydrogen in IL [37-38]. Remarkably, ILs themselves have also been used as hydrogen storage materials and not simply as solvent for the substrates and catalysts.

\subsection{Hydrogen-rich Molecules as Storage Media}

Hydrogen storage materials have to fulfil several requirements. Since hydrogen can be stored in its molecular form as gas or liquid, 


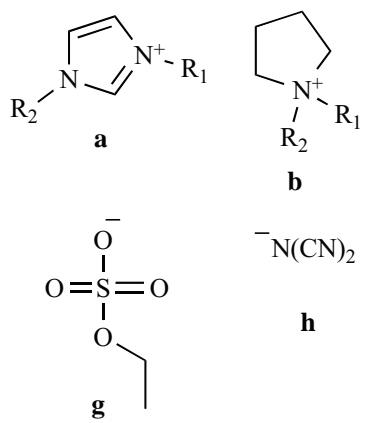<smiles>[R7][n+]1ccccc1</smiles><smiles>[R][N+]([R])([R])[R]</smiles><smiles>[R][P+]([R])([R])C</smiles>

d

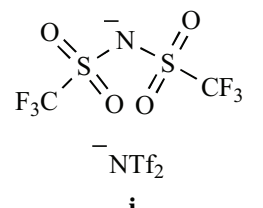<smiles></smiles>

$\overline{P F}_{6}$

1

Fig. (1). Selected examples for IL-cations and anions: (a) imidazolium, (b) pyrrolidinium, (c) pyridinium, (d) ammonium, (e) phosphonium and (f) guanidinium. The side-chains $\mathrm{R}_{1-6}$ are alkyl groups, which can also carry functionalities like alcohols, ethers, nitriles, etc. Usually weakly coordinating anions are used as counter-parts $(\mathrm{g}-\mathrm{l})$ : ethyl sulfate, dicyanamide, bistrifluoromethanesulfonylimide $\left(\mathrm{NTf}_{2}{ }^{-}\right)$, methyl sulfonate $\left(\mathrm{OMs}^{-}\right)$, tetrafluoroborate $\left(\mathrm{BF}_{4}{ }^{-}\right)$, hexafluorophosphate $\left(\mathrm{PF}_{6}^{-}\right)$, etc.<smiles>[H][Z8]([H])([H])[NH3+]</smiles>

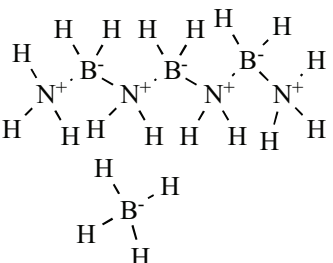<smiles>[13CH][13CH3]</smiles>
$+\mathrm{n} \mathrm{AB} \downarrow \downarrow-\mathrm{m} \mathrm{H}_{2}$

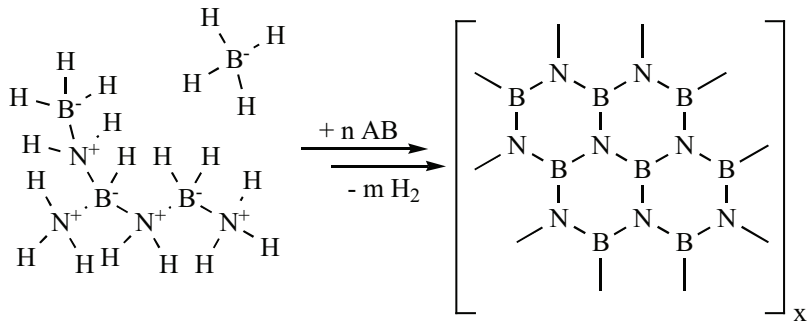

Scheme 1. Decomposition pathways of AB.

such molecular materials must comprise advantages in comparison to molecular hydrogen. The disadvantageous properties of molecular hydrogen are the low density in the gaseous form and the requirements to store it as compressed gas or in the liquid state. The amount of hydrogen required for a $500 \mathrm{~km}$ travel $(6 \mathrm{~kg}$ of $\mathrm{H} 2$ ) would need a tank volume of around $67 \mathrm{~m}^{3}$ under ambient conditions. Therefore, today $6 \mathrm{~kg}$ hydrogen is compressed into a tank with 260 litres volume at a pressure of 700 bar [4]. The total weight of such hydrogen tanks is $125 \mathrm{~kg}$. This means the gravimetric efficiency is only $4.8 \mathrm{wt} \%$. The cryogenic storage for liquid hydrogen is considered too inefficient in praxis due to evaporation of hydrogen. Moreover, problems arise from the required strong isolation of the tanks which results in further gravimetric inefficiency. In conclusion these disadvantages make it reasonable to store hydrogen in organic or inorganic materials where hydrogen is chemically bound in its protic and hydridic form. Thus, higher volumetric hydrogen density in the condensed phase is an obtainable target.

\subsubsection{Ammonia Borane}

The Lewis adduct of ammonia and borane is an interesting target compound and is in the focus of current research $[6,10,17,39$ 41]. This solid material is air and moisture stable and consists of $19.6 \mathrm{wt}-\%$ hydrogen. Its thermal treatment at $130{ }^{\circ} \mathrm{C}$ results in lib- eration of $14 \mathrm{wt} \%$ of gaseous hydrogen [4]. Unfavorable byproducts which occur in course of the decomposition reaction are ammonia, diborane and borazine. These by-products are critical because of their high volatility causing contamination of the gas stream and lowering efficiency due to incomplete hydrogen release. The complete dehydrogenation of $\mathrm{AB}$ needs temperatures of $>500{ }^{\circ} \mathrm{C}$. The dehydrogenation results in oligoamino boranes, polyamino boranes and insoluble polyborazylene (Scheme 1), which is highly stable in mechanical, chemical and thermal means.

Since the temperature to decompose ammonia borane completely is high, complete dehydrogenation is undesired. Thus partial dehydrogenation of $\mathrm{AB}$ releasing $\sim 14 \mathrm{wt} \%$ of hydrogen is considered as efficient hydrogen storage material.

The formation of the mentioned by-products is the major drawback and the regeneration of spent AB-based fuels is another major challenge. Recently, Sutton et al. presented encouraging results [42]. They dissolved AB spent fuel in liquid ammonia and reduced it with hydrazine resulting in the complete reformation of $\mathrm{AB}$, with nitrogen gas as the only by-product.

\subsubsection{Ammonia Borane Derivatives}

In recent years, some derivatives of ammonia borane have been studied as hydrogen storage materials. The following materials are 


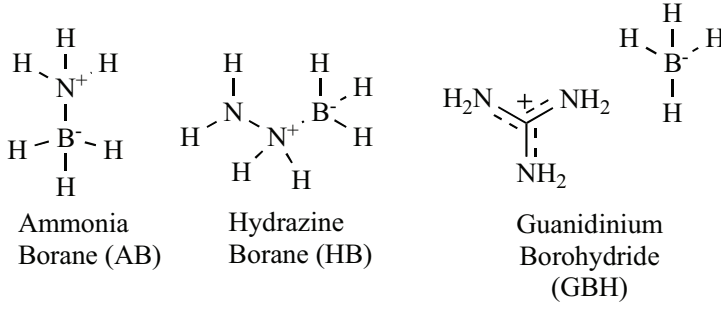<smiles>[NH2+]CC[15NH2]</smiles>

Ethylene Diamine Bisborane (EDB)<smiles></smiles>

Dimethylamine

Borane

$(\mathrm{DMAB} ; \mathrm{R}, \mathrm{R}=\mathrm{Me})$

Fig. (2). Selected AB-related hydrogen storage materials.

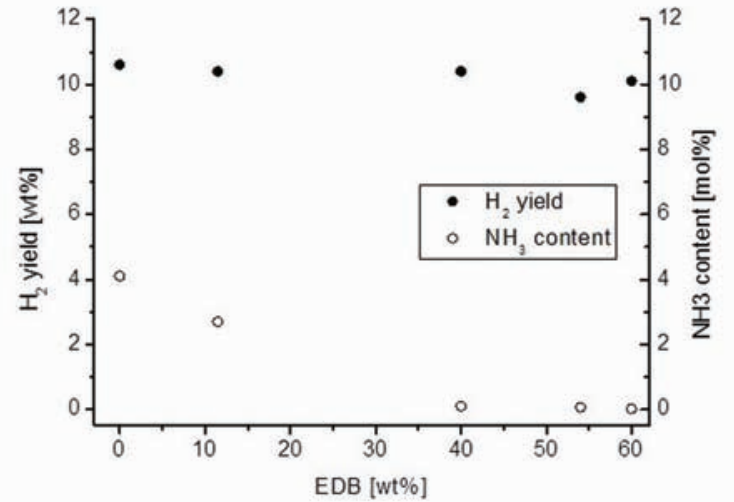

Fig. (3). GBH-EDB Self-Sustaining-Thermal-Decomposition. Mixture containing $60 \mathrm{wt} \%$ EDB is not self-sustaining [12].

considered as alternatives to $\mathrm{AB}$ : hydrazine borane (HB) [13], guanidinium borohydride (GBH) [12], ethylenediamine bisborane (EDB) [43], methylguanidinium borohydride (Me-GBH) [44] and different alkyl amine boranes (Fig. 2) [14, 45]. Another compound class between molecular and metal hydride storage materials are metal amido boranes, which are not discussed in this chapter [46].

Lentz and co-workers studied hydrazine borane, which provides a comparable weight efficiency as $\mathrm{AB}$ [13]. The major part of the hydrogen content in HB is thermally accessible, but the hydrogen generation can be efficiently improved by mixing HB with lithium hydride. The molar 1:1-mixture of $\mathrm{HB}$ and $\mathrm{LiH}$ results in a blend material with a hydrogen content of $14.8 \mathrm{wt} \%$ in comparison to $15.4 \mathrm{wt} \%$ of neat $\mathrm{HB}$. With this blend an experimental hydrogen release of $\sim 12 \mathrm{wt} \%$ has been realized at $150{ }^{\circ} \mathrm{C}$ within $4.5 \mathrm{~h}$. Blending $\mathrm{HB}$ with a hydride-donor is a consequent optimization, as pure $\mathrm{HB}$ consists of four acidic and three hydridic hydrogen atoms, thus, it contains one excess acidic hydrogen. The authors reported that they only found ammonia as impurity in the hydrogen gas stream in the range $<1 \%$. The solid by-products showed reactivity towards water and are insoluble in organic solvents. The double borane adduct of hydrazine, hydrazine bisborane, has a hydrogen content a little higher than HB, but is not considered due to stability problems. The authors reported rapid heating or temperatures above $160{ }^{\circ} \mathrm{C}$ caused explosive decomposition.

Groshens and Hollins reported remarkable results with guanidinium borohydride $(\mathrm{GBH})$ and its blends [12]. In GBH, the protic moieties are incorporated in the guanidinium cation and the counter-ion contains the hydrides rendering a content of $10.8 \mathrm{wt} \%$ of hydrogen gas theoretically and $10.6 \mathrm{wt} \%$ experimentally. As the thermal decomposition is exothermic, the hydrogen generation reaction remains self-sustaining after initial heating. This material can nearly be completely dehydrogenated, though about $5 \mathrm{~mol} \%$ ammonia is found in the gas stream. The idea of blending arises from the imbalance of protic and hydridic hydrogen atoms in $\mathrm{GBH}$ : there are two surplus protic hydrogen atoms in GBH. As ideal hydride source for a GBH-blend, ethylene diamine bisborane (EDB) was chosen, carrying two excess hydrides. The hydrogen yields of GBH-EDB blends are high and the undesired ammonia formation is maintained on a low level, especially using an equimolar mixture GBH and EDB (Fig. 3). The 40:60 wt\% GBH-EDB blend yields $10.1 \mathrm{wt} \%$ of hydrogen with a distinctly lower ammonia impurity of only $0.026 \mathrm{~mol} \%$. The major drawback of this material blend is its solid state. Pure EDB is also interesting in terms of high efficiency in comparison to the previously mentioned blend [43]. One advantage of this material is the high purity of the generated hydrogen as no impurities are detectable below $200^{\circ} \mathrm{C}$. The generation of hydrogen using EDB is comparably fast as ammonia borane based systems.

\subsubsection{Formic Acid}

The catalytic dehydrogenation of formic acid (FA) yielding equimolar amounts of dihydrogen and carbon dioxide has drawn some attention in the last years (Scheme 2). [9, 47-52] Formic acid contains only $4.4 \mathrm{wt} \%$ hydrogen, less than the previous mentioned materials. The abundance of carbon dioxide as substrate enhances the attraction of formic acid as simple and cheap hydrogen storage material. For synthetic applications formic acid is also suitable as hydrogen source for catalytic transfer-hydrogenation reactions [5356].

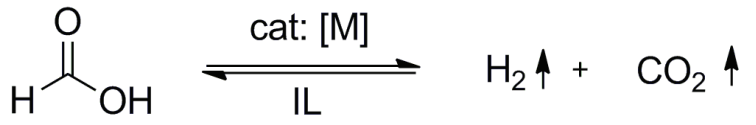

Scheme 2. Reversible splitting of formic acid.

\section{IONIC LIQUIDS IN HYDROGEN STORAGE SYSTEMS}

ILs are interesting for different applications in the field of hydrogen storage due to their physico-chemical properties. For example, a low weight and hydrogen rich IL can be directly used as hydrogen storage material. Moreover ILs may be applied as solvent, as a promoting solvent for dehydrogenation, as co-catalyst or as stabilizer for e. g. metal nanoparticles.

\subsection{ILs as Hydrogen Storage Materials}

The GBH derivative Methyl-GBH contains one methyl group on a guanidinium nitrogen, and this modification results in a decrease of the melting point, hence, formation of an IL which is suitable as hydrogen source (Fig. 4) [44].<smiles>CN=[C+]=N</smiles>

Fig. (4). Structure of methyl guanidinium borohydride (Me-GBH) 


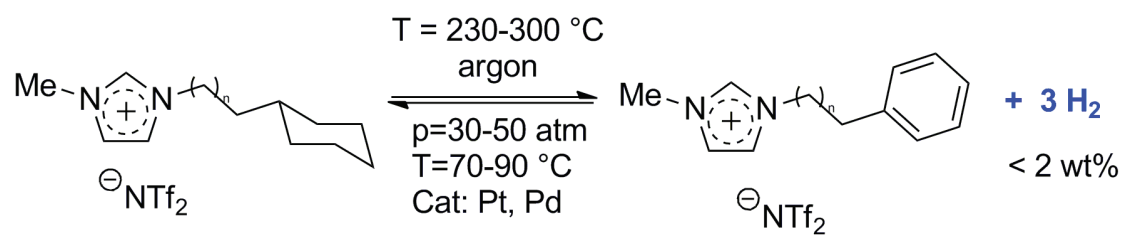

$$
\mathrm{n}=0-2 \quad \mathrm{R}=\mathrm{H}, \mathrm{Cy}, \mathrm{Ph}
$$

Scheme 3. Structure of cyclohexyl-ILs for hydrogen storage [58].

$$
\left[\mathrm{Rh}\left(\mathrm{O}_{2} \mathrm{CC}_{5} \mathrm{H}_{11}\right)_{2}\right]_{2}+6 \mathrm{Me}_{2} \mathrm{HNBH}_{3} \longrightarrow 2 / \mathrm{nRh}(\mathrm{O})_{n}+4\left[\mathrm{Me}_{2} \mathrm{H}_{2} \mathrm{~N}^{+}\left[\mathrm{C}_{5} \mathrm{H}_{11} \mathrm{CO}_{2}\right]^{-}+2 \mathrm{~B}_{2} \mathrm{H}_{6}+{ }_{2}^{\mathrm{Ce}_{2} \mathrm{~N}-\mathrm{NMe}_{2}}\right.
$$

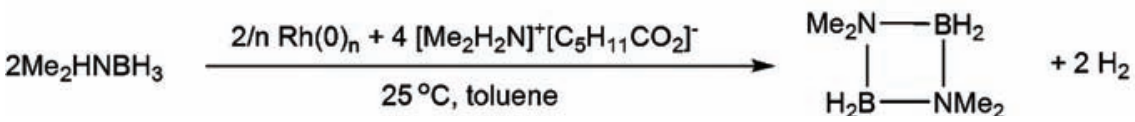

Scheme 4. Rhodium nanoparticle formation and catalytic decomposition of DMAB. Reprinted with permission from [59]. Copyright (2009) American Chemical Society.

Me-GBH contains smaller amounts of accessible hydrogen than GBH. The methyl group distorts the symmetry of the cation, thus, resulting in a lower melting point of this salt [57]. In particular, the Me-GBH is the first room temperature IL (m.p. $-5^{\circ} \mathrm{C}$ ) which can be easily dehydrogenated with a reasonably high hydrogen capacity of $9.0 \mathrm{wt} \%$. However, kinetic studies focusing on thermal dehydrogenation at $75^{\circ} \mathrm{C}$ showed that the decomposition is too slow and ineffective for application. Moreover, the studies showed that the decomposition also causes mass loss which exceeds the theoretical capacity of the substrate, thus this cannot be assigned to hydrogen evolution. At higher temperatures $\left(>120^{\circ} \mathrm{C}\right)$ amounts of ammonia are detectable in the gas stream. The quantification of the hydrogen generation was calculated to be $9.0 \mathrm{wt} \%$ based on yields determined by TGA and volumetric measurements. The dehydrogenation product of Me-GBH is solid and insoluble in the IL. Additionally, Wilkinson's catalyst $\left[\left(\mathrm{PPh}_{3}\right)_{3} \mathrm{RhCl}\right]$ and $\mathrm{FeCl}_{2}$ have been tested to improve the rate and extent of hydrogen generation with moderate success.

Another attempt to incorporate a hydrogen carrier into an IL was performed by attaching a side-chain containing a cyclohexyl moiety to an imidazolium cation [58]. Here, $\mathrm{Pd} / \mathrm{C}$ was used at elevated temperatures during the cyclohexyl dehydrogenation and rehydrogenation process (Scheme 3). Even though storage capacity is too low, this work represents the first report where an IL has been applied as hydrogen storage material. The drawbacks of this system are the high temperatures $\left(300^{\circ} \mathrm{C}\right)$ for fast dehydrogenation and the low hydrogen storage capacity. The thermal stability of some of the employed ILs is remarkable.

\subsection{ILs as Stabilizing Agents for Nanoparticles for Catalytic Dehydrogenation}

The dimethyl amino borane (DMAB) is an ideal model system for mechanistic studies, since the methyl groups suppress further dehydrogenation after one equivalent of dihydrogen is generated, hence, inhibits formation of oligomeric product mixtures. The catalytic dehydrogenation of disubstituted amino borane compounds leads to selective formation of cyclic dimers and trimers at room temperature [15]. The studies of these model systems are mechanistically important, rather than for the application as hydrogen storage materials owing to the lower accessible hydrogen content in comparison to the previously discussed materials. The dehydrogenation of DMAB proceeds via the diammoniate of diborane to the cyclic dimer [59]. The application of excess DMAB in presence of dimeric rhodium(II)-hexanoate lead to the formation of $\mathrm{Rh}(0)$ nanoparticles and the IL dimethyl ammonium hexanoate (Scheme 4). These nanoparticles $(\sim 2 \mathrm{~nm})$ show high activity for the catalytic dehydrogenation of DMAB at low temperature yielding high conversions (Scheme 4). The in-situ generated IL dimethyl ammonium hexanoate acts as protecting agent for the nanoparticles.

\subsection{ILs as Active/Supporting Solvents}

In other studies it has been shown that certain ILs are capable to act as promoting solvents for the dehydrogenation of amine boranes (Figs. 5 and 6) [17, 60].

The IL-promoted dehydrogenation of $\mathrm{AB}$ in IL mixtures consisting of $50 \mathrm{wt} \%$ of $\mathrm{AB}$ at $85{ }^{\circ} \mathrm{C}$ shows that certain ILs are capable to release more than two equivalents of hydrogen gas per $\mathrm{AB}$ (Fig. 6; A-C). Most ILs promote dehydrogenation significantly, even though the initial rates of generated $\mathrm{H}_{2}$ are not related to the overall amount of released hydrogen. Only in one case (Entry J) the IL does not show any promoting effect, hence the dehydrogenation efficiency is equivalent to the thermal decomposition of neat ammonia borane (Fig. 6).

The dehydrogenation of $\mathrm{AB}$ promoted by [BMIM]Cl was studied in more detail [60]. The in-depth studies showed that reaction rates as well as total hydrogen yield can be further improved (Fig. 7). At a rather low temperature of $85^{\circ} \mathrm{C}$ the hydrogen yield of $\mathrm{AB}$ can be significantly enhanced in presence of [BMIM]Cl in a $50 \mathrm{wt} \%$ mixture, in comparison to neat ammonia borane, also regarding weight-efficiency in both systems (Fig. 7 - left).

Interestingly, the gas analyses revealed that only residual amounts of borazine are present, this indicates that borazine formation is suppressed or it completely dissolves in the IL. As shown above, [BMIM]Cl efficiently promotes dehydrogenation and the induction period is precluded completely. These advantages remain when IL concentration is lowered to $20 \mathrm{wt} \%$. The IL supported $\mathrm{H}_{2}$ generation from $\mathrm{AB}$ at $75^{\circ} \mathrm{C}$ yields an equal amount of $\mathrm{H}_{2}$ as the decomposition of neat $\mathrm{AB}$ at $85^{\circ} \mathrm{C}$. Moreover, in IL the reaction is faster and no induction period occurs. The reaction is quite sensitive towards process temperature, where hydrogen yield increases 
<smiles>CCCCn1cc[n+](C)c1</smiles><smiles>CCCCn1cc[n+](C)c1</smiles>

$\mathrm{BF}_{4}^{-}$<smiles>CCCCn1cc[n+](C)c1</smiles><smiles>CCCCn1cc[n+](C)c1</smiles><smiles>CCCCn1cc[n+](C)c1</smiles><smiles>COS(=O)(=O)[O-]</smiles>

$[\mathrm{BMIM}] \mathrm{Cl}$

$[\mathrm{BMIM}] \mathrm{BF}_{4}$

$[\mathrm{BMIM}] \mathrm{PF}_{6}$

[BMIM]OTf [MMIM] $\left[\mathrm{MeSO}_{4}\right]$<smiles>CCCCn1cc[n+](C)c1C</smiles>

[BMMIM]Cl<smiles>CCOS(=O)(=O)[O-]</smiles>

[EMMIM] $\left[\mathrm{EtSO}_{4}\right]$
OTf $^{-}$<smiles>CCn1cc[n+](C)c1C</smiles>

[EMMIM]OTf<smiles>CCCCCn1cc[n+](C)c1C</smiles>

[EMMIM] $\mathrm{Tf}_{3} \mathrm{C}$

Fig. (5). Structures of ILs applied as promoting media of AB dehydrogenation [60].

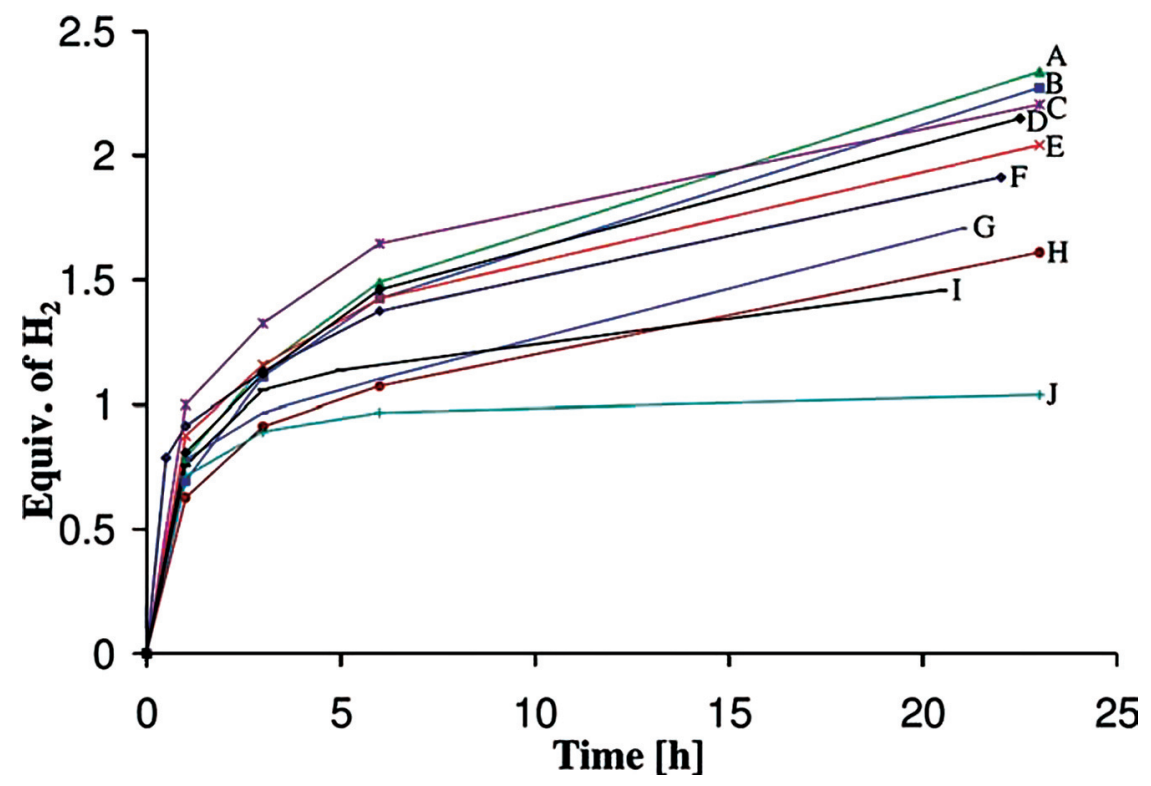

Fig. (6). $\mathrm{H}_{2}$-release measurements (Toepler pump) of the reaction of $50 \mathrm{wt} \% \mathrm{AB}\left(250 \mathrm{mg}\right.$ ) at $85^{\circ} \mathrm{C}$ in $250 \mathrm{mg}$ of (A) [BMMIM]Cl, (B) [BMIM]Cl, (C) [EM-

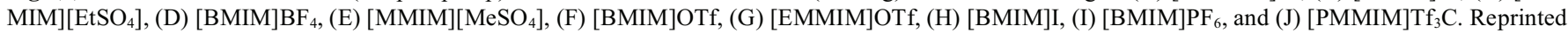
with permission from [60]. Copyright (2009) American Chemical Society.

slightly and reaction time is significantly shorter. At $85^{\circ} \mathrm{C}$ 2.1 equivalents of $\mathrm{H}_{2}$ are released within $\sim 4.1$ hours, in comparison, at $110{ }^{\circ} \mathrm{C} 2.3$ equivalents $\mathrm{H}_{2}$ are released in less than 0.5 hours.

\subsection{ILs as Solvents for Catalytic AB Dehydrogenation}

Certain metal complexes are suitable to catalyse the dehydrogenation of ammonia borane based materials, thus reaction rate and process temperature can be improved, which are crucial for hydrogen storage systems in transportation $[15,61]$. In combination with ILs as promoting solvents for the dehydrogenation of $\mathrm{AB}$ derivatives, the catalytic dehydrogenation can be further accelerated. For example transition metal based pre-catalysts, such as $\mathrm{Rh}, \mathrm{Ru}, \mathrm{Pd}$ or
$\mathrm{Ni}$, decrease the process temperature of $\mathrm{AB}$ dehydrogenation significantly $\left(45-85^{\circ} \mathrm{C}\right)$ and hydrogen yield is improved at the same time (Fig. 8) [16].

The applied metal precursors have not been further investigated regarding the active species, however, most of them are known to form metal nanoparticles in presence of a reductant or undergo thermal decomposition in ILs [23]. Therefore, one may consider that at least in some cases metal(0) nanoparticles play a role in the catalytic dehydrogenation of ammonia borane. The reaction monitoring showed that the majority of the applied precursors (5 mol\%) undoubtedly accelerate the reaction and improve yields significantly. 

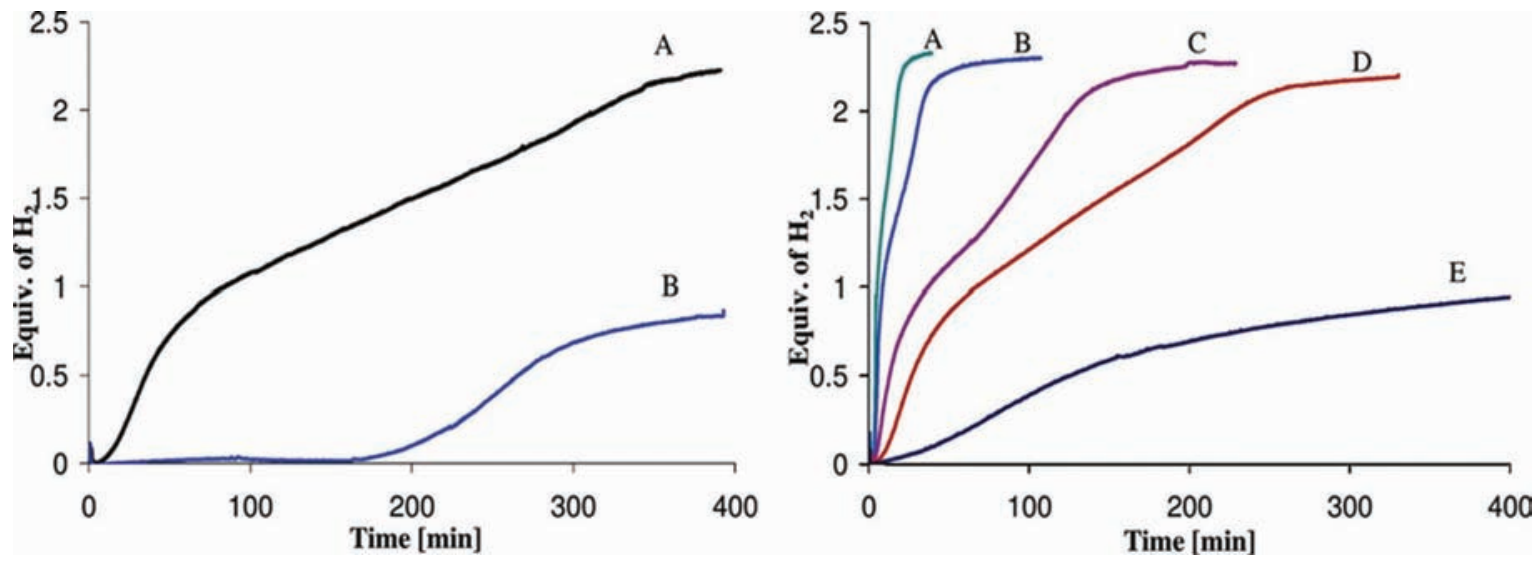

Fig. (7). (Left) $\mathrm{H}_{2}$-release measurements at $85^{\circ} \mathrm{C}$ of: (A) $50 \mathrm{wt} \% \mathrm{AB}$ in $[\mathrm{BMIM}] \mathrm{Cl}$ and (B) solid-state $\mathrm{AB}$ (Right) $\mathrm{H}_{2}$-release measurements of $50 \mathrm{wt} \% \mathrm{AB}$ in [BMIM] Cl at (A) $110^{\circ} \mathrm{C}$, (B) $105^{\circ} \mathrm{C}$, (C) $95^{\circ} \mathrm{C}$, (D) $85^{\circ} \mathrm{C}$, and (E) $75^{\circ} \mathrm{C}$. Reprinted with permission from [60]. Copyright (2009) American Chemical Society.

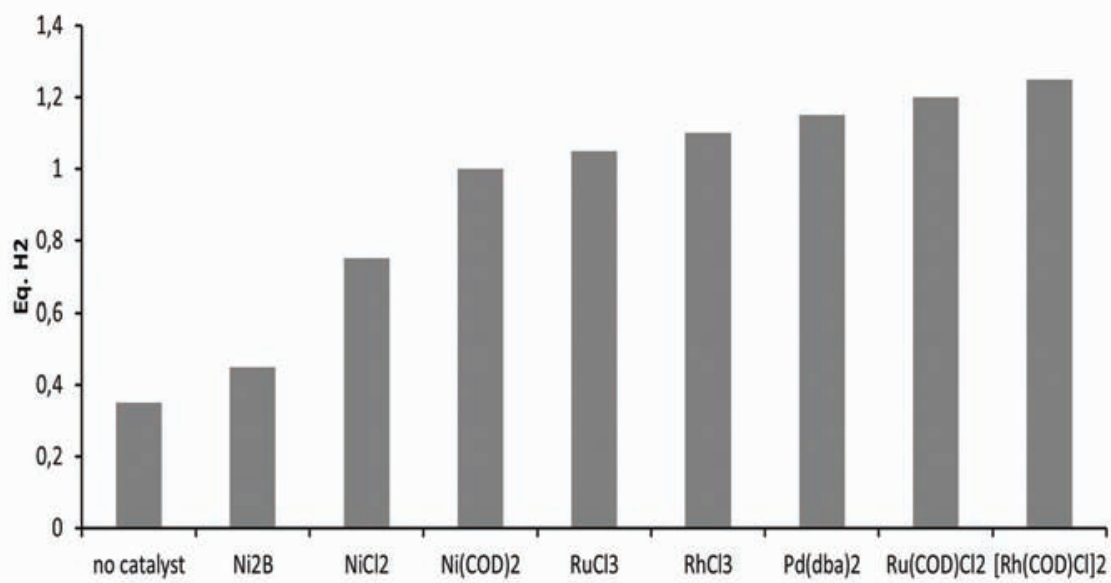

Fig. (8). Hydrogen evolution from $\mathrm{AB}-$ decomposition at $65^{\circ} \mathrm{C}$ after $4 \mathrm{~h}$ catalyzed by different metal catalyst-precursors. Adapted from Ref. [16].

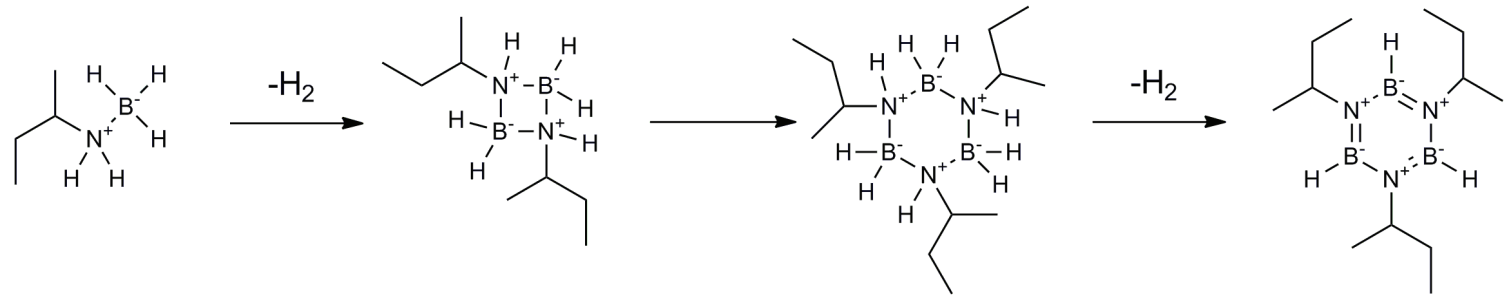

Scheme 5. Trimerisation of SBAB to the corresponding borazine derivative during hydrogen production [14].

Another derivative of $\mathrm{AB}$, sec-butyl amine borane (SBAB), blended with $\mathrm{AB}$ can be dehydrogenated catalytically in IL [14]. Interestingly, the dehydrogenation of this blend in [EMIM] $\left[\mathrm{EtSO}_{4}\right]$ leads via trimerisation to a soluble mono-molecular borazine derivative and oligomerisation to insoluble polyamino boranes is suppressed completely (Scheme 5). The weight efficiency drops down to $5 \mathrm{wt} \%$ due to the alky chain. This catalytic dehydrogenation used $1 \mathrm{~mol} \%\left[\mathrm{RuCl}_{2}\left(\mathrm{PMe}_{4}\right)_{3}\right]$ at $80^{\circ} \mathrm{C}$. Details about the gas stream purity have not been reported.

\subsection{FUNCTIONALIZED ILS FOR CATALYTIC DECOM- POSITION OF FORMIC ACID}

Functionalised ILs have different applications as task-specific designer solvents for example in the dehydrogenation of formic acid (see Scheme 2). In this example a basic amine-functionality is incorporated into the IL side-chain. The imidazolium-based ILs with a 1-(N,N-diethylamino)-ethyl-3-methylimidazolium cation $\left(\left[(\mathrm{Et})_{2} \mathrm{NEMIM}\right]^{+}\right)$(see Fig. 9) act as solvent for the catalyst, are miscible with formic acid and the amine-functionality acts as immobilised basic co-catalyst in the dehydrogenation of formic acid (Fig. 9) $[9,62]$.

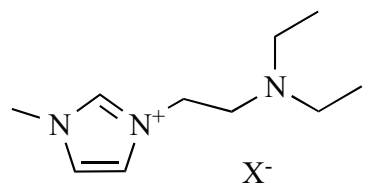

Fig. (9). Structure of the amino-functionalized ILs containing $\left[(\mathrm{Et})_{2} \mathrm{NEMIM}\right]^{+}[9,62]$.

Several anions $\left(\mathrm{Cl}^{-}, \mathrm{BF}_{4}^{-}\right.$, OTf, $\mathrm{NTf}_{2}^{-}$and $\left.\mathrm{HCO}_{2}^{-}\right)$with this cation were tested for the catalytic dehydrogenation of formic acid 


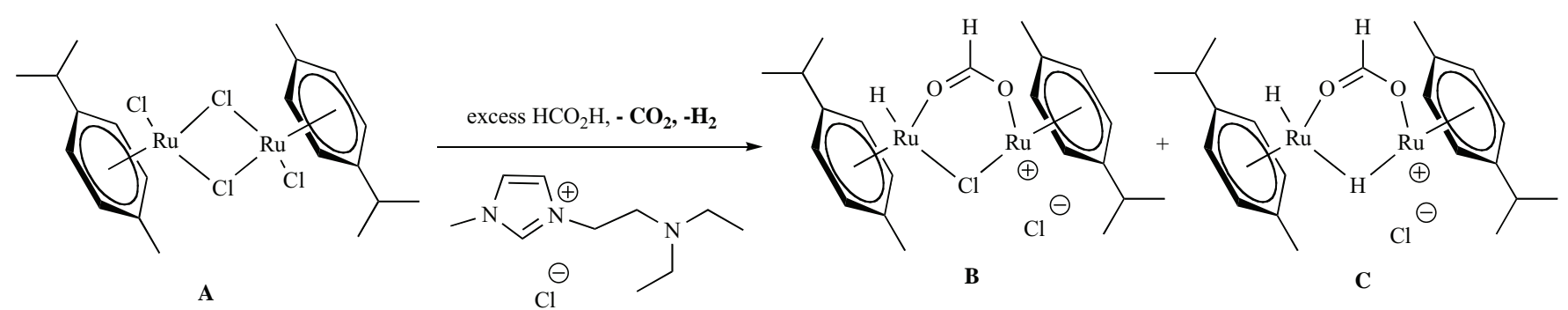

Scheme 6. Reactivity of $\left[(\mathrm{p} \text {-cymene }) \mathrm{RuCl}_{2}\right]_{2} \mathbf{A}$ in presence of formic acid and $\left[(\mathrm{Et})_{2} \mathrm{NEMIM}\right] \mathrm{Cl}$.

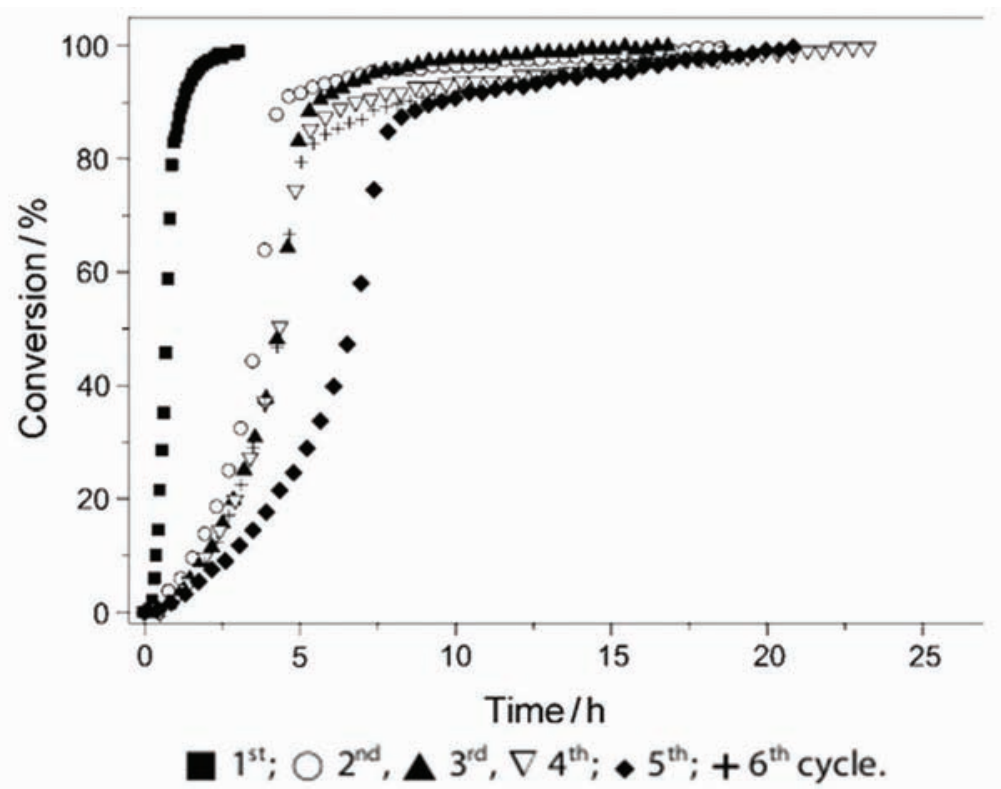

Fig. (10). Reaction profiles for formic acid decomposition catalyzed by [(p-cymene) $\left.\mathrm{RuCl}_{2}\right]$ in $\left[(\mathrm{Et})_{2} \mathrm{NEMIM}\right] \mathrm{Cl}$ at $80{ }^{\circ} \mathrm{C}$ for 6 cycles. Reprinted with permission from [9]. Copyright (2010) John Wiley and Sons.

with the dimeric ruthenium pre-catalyst $\left[(\mathrm{p} \text {-cymene }) \mathrm{RuCl}_{2}\right]_{2} \mathbf{A}$. Depending on the reaction conditions and the used IL the TOFs varied from $36 \mathrm{~h}^{-1}$ (no add. base) to $627 \mathrm{~h}^{-1}$ (add. base). Further studies showed that in presence of formic acid the dichloro-bridged ruthenium dimer $\mathbf{A}$ is converted into the corresponding formate/chloro-bridged $\left[(\mathrm{p} \text {-cymene }) \mathrm{RuCl}\left(\mathrm{HCO}_{2}\right)\right]_{2} \quad \mathbf{B}$ and formate/hydride-bridged $\left[(\mathrm{p} \text {-cymene }) \mathrm{RuH}\left(\mathrm{HCO}_{2}\right)\right]_{2} \mathbf{C}$. This indicates that in the catalytic cycle formate-bridged ruthenium dimers play a crucial role (Scheme 6). The reported TOFs of up to $1684 \mathrm{~h}^{-1}$ were calculated with the assumption of a dimeric ruthenium complex species. Notably no monomeric ruthenium species have been detected.

It has been shown that small IL amounts result in a more efficient system than high co-catalyst loadings. Due to the high viscosity of the pure IL, the mixtures viscosity increases in the course of the reaction. The viscosity may be accounted for the decelerated reaction resulting from higher co-catalyst, i.e. IL, loadings. The robustness of this system has been shown in six recycling experiments that were conducted without any precautions against air or moisture. After the high activity in the first run, the reaction monitoring showed similar profiles for the next runs, except the fifth (Fig. 10).

The catalyst precursor $\left[(\mathrm{p} \text {-cymene }) \mathrm{RuCl}_{2}\right]_{2}$ in IL can also be applied in the dehydrogenative conversion of biomass, such as cellulose(-derivatives). Some strongly solvating ILs are suitable to dissolve these (in classical solvents hardly soluble) materials. Thus, these substrates become accessible for homogeneous dehydrogenation [63]. Studies about the dehydrogenation of these carbohydrates revealed that e.g. glucose is not converted into the corresponding dehydrogenated product, but it undergoes thermal decomposition releasing formic acid which is then catalytically converted into $\mathrm{CO}_{2}$ and $\mathrm{H}_{2}$. Moreover, wood was dissolved in the IL 1-ethyl-3methylimidazolium methyl-methylphosphonate, thermally converted into formic acid at $180^{\circ} \mathrm{C}$ and subsequently dehydrogenated by the ruthenium complex (Scheme 7). The high process temperatures necessitate ILs with high thermal stability.

\section{CONCLUSION AND OUTLOOK}

The research field of molecular hydrogen storage materials still provides several challenges to be overcome. ILs seem to be capable to resolve some aspects in different points. Besides the rare examples of ILs as hydrogen storage materials, they serve in several ways for the hydrogen generation: (I) application as highly thermally and chemically stable solvents, (II) promoting solvents for dehydrogenation of the hydrogen-rich substrates, (III) co-catalyst in case of incorporation of a Lewis-base, and (IV) the superior solubilisation properties of ILs are promising aspects in search of liquid hydrogen storage systems which remain liquid after complete hydrogen release. The only drawback of ILs as additive to pure or blended hydrogen storage materials is the additional weight in the system, resulting in a lower gravimetric efficiency. However, it has been shown that this drawback can be fully compensated as the IL- 


$$
\underbrace{(\mathrm{OH}}_{\mathrm{OH}}
$$

Scheme 7. Thermal conversion of glucose and catalytic dehydrogenation of formic acid in IL [63].

based systems gave much higher hydrogen yields in shorter reaction times than the dehydrogenation of neat hydrogen-rich materials.

\section{CONFLICT OF INTEREST}

The author(s) confirm that this article content has no conflicts of interest.

\section{ACKNOWLEDGEMENTS}

The authors want to acknowledge financial support from the Ministerium für Innovation, Wissenschaft und Forschung NRW (MIWF-NRW) for financial support within the Energy Research Program for the Scientist Returnee Award for M.H.G. Prechtl. S. Sahler wants to thank M. Kessler for helpful discussion.

\section{REFERENCES}

[1] Hamilton, C. W.; Baker, R. T.; Staubitz, A.; Manners, I. B-N compounds for chemical hydrogen storage. Chem. Soc. Rev., 2009, 38 (1), 279-293.

[2] Schlapbach, L.; Zuttel, A. Hydrogen-storage materials for mobile applications. Nature, 2001, 414 (6861), 353-358.

[3] Felderhoff, M.; Weidenthaler, C.; von Helmolt, R.; Eberle, U. Hydrogen storage: the remaining scientific and technological challenges. Phys. Chem. Chem. Phys., 2007, 9 (21), 2643-2653.

[4] Eberle, U.; Felderhoff, M.; Schuth, F. Chemical and Physical Solutions for Hydrogen Storage. Angew. Chem.-Int. Edit., 2009, 48 (36), 6608-6630.

[5] Marder, T. B. Will we soon be fueling our automobiles with ammoniaborane? Angew. Chem.-Int. Ed., 2007, 46 (43), 8116-8118.

[6] Staubitz, A.; Robertson, A. P. M.; Manners, I. Ammonia-Borane and Related Compounds as Dihydrogen Sources. Chem. Rev., 2010, 110 (7), 4079-4124.

[7] Fellay, C.; Dyson, P. J.; Laurenczy, G. A viable hydrogen-storage system based on selective formic acid decomposition with a ruthenium catalyst. Angew. Chem.-Int. Ed., 2008, 47 (21), 3966-3968.

[8] Loges, B.; Boddien, A.; Junge, H.; Beller, M. Controlled generation of hydrogen from formic acid amine adducts at room temperature and application in $\mathrm{H}(2) / \mathrm{O}(2)$ fuel cells. Angew. Chem.-Int. Edit., 2008, 47 (21), 3962-3965.

[9] Scholten, J. D.; Prechtl, M. H. G.; Dupont, J. Decomposition of Formic Acid Catalyzed by a Phosphine-Free Ruthenium Complex in a Task-Specific Ionic Liquid. ChemCatChem, 2010, 2 (10), 1265-1270.

[10] Stephens, F. H.; Pons, V.; Baker, R. T. Ammonia - borane: the hydrogen source par excellence? Dalton Trans., 2007, (25), 2613-2626.

[11] Dupont, J.; Suarez, P. A. Z. Physico-chemical processes in imidazolium ionic liquids. Phys. Chem. Chem. Phys., 2006, 8 (21), 2441-2452.

[12] Groshens, T. J.; Hollins, R. A. New chemical hydrogen storage materials exploiting the self-sustaining thermal decomposition of guanidinium borohydride. Chem. Commun., 2009, (21), 3089-3091.

[13] Hugle, T.; Kuhnel, M. F.; Lentz, D. Hydrazine Borane: A Promising Hydrogen Storage Material. J. Am. Chem. Soc., 2009, 131 (21), 7444-7446.

[14] Mal, S. S.; Stephens, F. H.; Baker, R. T. Transition metal catalysed dehydrogenation of amine-borane fuel blends. Chem. Commun., 2011, 47 (10), 2922-2924.

[15] Jaska, C. A.; Temple, K.; Lough, A. J.; Manners, I. Transition metalcatalyzed formation of boron-nitrogen bonds: Catalytic dehydrocoupling of amine-borane adducts to form aminoboranes and borazines. J. Am. Chem. Soc., 2003, 125 (31), 9424-9434.

[16] Wright, W. R. H.; Berkeley, E. R.; Alden, L. R.; Baker, R. T.; Sneddon, L. G. Transition metal catalysed ammonia-borane dehydrogenation in ionic liquids. Chem. Commun., 2011, 47 (11), 3177-3179.

[17] Bluhm, M. E.; Bradley, M. G.; Butterick, R.; Kusari, U.; Sneddon, L. G. Amineborane-based chemical hydrogen storage: Enhanced ammonia borane dehydrogenation in ionic liquids. J. Am. Chem. Soc., 2006, 128 (24), 77487749 .

[18] Scholten, J. D.; Leal, B. C.; Dupont, J. Transition Metal Nanoparticle Catalysis in Ionic Liquids. ACS Catal., 2012, 2 (1), 184-200.
[19] Prechtl, M. H. G.; Scholten, J. D.; Dupont, J., Palladium Nanoscale Catalysts in Ionic Liquids: Coupling and Hydrogenation Reactions, Ionic Liquids: Applications and Perspectives. In Ionic Liquids: Applications and Perspectives, Kokorin, A., Ed. InTech: Vienna, 2011; pp 393-414.

[20] Dupont, J.; Scholten, J. D.; Prechtl, M. H. G., Green Processes. In Handbook of Green Chemistry, Wiley Interscience: Weinheim, 2011; Vol. 8.

[21] Dupont, J.; Scholten, J. D. On the structural and surface properties of transition-metal nanoparticles in ionic liquids. Chem. Soc. Rev., 2010, 39 (5), 1780-1804.

[22] Prechtl, M. H. G.; Scholten, J. D.; Dupont, J. Carbon-Carbon Cross Coupling Reactions in Ionic Liquids Catalysed by Palladium Metal Nanoparticles. Molecules, 2010, 15 (5), 3441-3461.

[23] Migowski, P.; Dupont, J. Catalytic applications of metal nanoparticles in imidazolium ionic liquids. Chem.-Eur. J., 2007, 13 (1), 32-39.

[24] Dupont, J.; de Souza, R. F.; Suarez, P. A. Z. Ionic liquid (molten salt) phase organometallic catalysis. Chem. Rev., 2002, 102 (10), 3667-3691.

[25] Dupont, J. On the solid, liquid and solution structural organization of imidazolium ionic liquids. J. Brazil. Chem. Soc., 2004, 15 (3), 341-350.

[26] Hallett, J. P.; Welton, T. Room-Temperature Ionic Liquids: Solvents for Synthesis and Catalysis. 2. Chem. Rev., 2011, 111 (5), 3508-3576.

[27] Welton, T. Room-temperature ionic liquids. Solvents for synthesis and catalysis. Chem. Rev., 1999, 99 (8), 2071-2083.

[28] Krossing, I.; Slattery, J. M.; Daguenet, C.; Dyson, P. J.; Oleinikova, A.; Weingartner, H. Why are ionic liquids liquid? A simple explanation based on lattice and solvation energies. J. Am. Chem. Soc., 2006, 128 (41), $13427-$ 13434.

[29] Wilkes, J. S. A short history of ionic liquids - from molten salts to neoteric solvents. Green Chem., 2002, 4 (2), 73-80.

[30] Cui, Y. G.; Biondi, I.; Chaubey, M.; Yang, X.; Fei, Z. F.; Scopelliti, R.; Hartinger, C. G.; Li, Y. D.; Chiappe, C.; Dyson, P. J. Nitrile-functionalized pyrrolidinium ionic liquids as solvents for cross-coupling reactions involving in situ generated nanoparticle catalyst reservoirs. Phys. Chem. Chem. Phys., 2010, 12 (8), 1834-1841.

[31] Yang, X.; Fei, Z. F.; Geldbach, T. J.; Phillips, A. D.; Hartinger, C. G.; Li, Y D.; Dyson, P. J. Suzuki coupling reactions in ether-functionalized ionic liquids: The importance of weakly interacting cations. Organometallics, 2008, 27 (15), 3971-3977.

[32] Fei, Z. F.; Zhao, D. B.; Pieraccini, D.; Ang, W. H.; Geldbach, T. J.; Scopelliti, R.; Chiappe, C.; Dyson, P. J. Development of nitrilefunctionalized ionic liquids for $\mathrm{C}-\mathrm{C}$ coupling reactions: Implication of carbene and nanoparticle catalysts. Organometallics, 2007, 26 (7), 15881598 .

[33] Chiappe, C.; Pieraccini, D.; Zhao, D. B.; Fei, Z. F.; Dyson, P. J. Remarkable anion and cation effects on Stille reactions in functionalised ionic liquids. Adv. Synth. Catal., 2006, 348 (1-2), 68-74.

[34] Zhao, D. B.; Fei, Z. F.; Geldbach, T. J.; Scopelliti, R.; Dyson, P. J. Nitrilefunctionalized pyridinium ionic liquids: Synthesis, characterization, and their application in carbon - Carbon coupling reactions. J. Am. Chem. Soc., 2004, 126 (48), 15876-15882.

[35] Dupont, J. From Molten Salts to Ionic Liquids: A "Nano" Journey. Acc. Chem. Res., 2011, 44 (11), 1223-1231.

[36] Xu, L.; Chen, W.; Xiao, J. Heck Reaction in Ionic Liquids and the in Situ Identification of N-Heterocyclic Carbene Complexes of Palladium. Organometallics, 2000, 19 (6), 1123-1127.

[37] Anthony, J. L.; Maginn, E. J.; Brennecke, J. F. Solubilities and thermodynamic properties of gases in the ionic liquid 1-n-butyl-3methylimidazolium hexafluorophosphate. J. Phys. Chem. B, 2002, 106 (29), 7315-7320.

[38] Jacquemin, J.; Gomes, M. F. C.; Husson, P.; Majer, V. Solubility of carbon dioxide, ethane, methane, oxygen, nitrogen, hydrogen, argon, and carbon monoxide in 1-butyl-3-methylimidazolium tetrafluoroborate between temperatures $283 \mathrm{~K}$ and $343 \mathrm{~K}$ and at pressures close to atmospheric. $J$. Chem. Thermodyn., 2006, 38 (4), 490-502.

[39] Basu, S.; Zheng, Y.; Gore, J. P. An experimental study of neat and ionic liquid-aided ammonia borane thermolysis. J. Power Sources, 2011, 196 (2), 734-740.

[40] Al-Kukhun, A.; Hwang, H. T.; Varma, A. A Comparison of Ammonia Borane Dehydrogenation Methods for Proton-Exchange-Membrane Fuel Cell Vehicles: Hydrogen Yield and Ammonia Formation and Its Removal. Ind. Eng. Chem. Res., 2011, 50 (15), 8824-8835. 
[41] Ahluwalia, R. K.; Peng, J. K.; Hua, T. Q. Hydrogen release from ammonia borane dissolved in an ionic liquid. Int. J. Hydrogen Energ., 2011, 36 (24), 15689-15697.

[42] Sutton, A. D.; Burrell, A. K.; Dixon, D. A.; Garner, E. B.; Gordon, J. C.; Nakagawa, T.; Ott, K. C.; Robinson, P.; Vasiliu, M. Regeneration of Ammonia Borane Spent Fuel by Direct Reaction with Hydrazine and Liquid Ammonia. Science, 2011, 331 (6023), 1426-1429.

[43] Neiner, D.; Karkamkar, A.; Bowden, M.; Choi, Y. J.; Luedtke, A.; Holladay, J.; Fisher, A.; Szymczak, N.; Autrey, T. Kinetic and thermodynamic investigation of hydrogen release from ethane 1,2-di-amineborane. Energ. Environ. Sci., 2011, 4 (10), 4187-4193.

[44] Doroodian, A.; Dengler, J. E.; Genest, A.; Rosch, N.; Rieger, B. Methylguanidinium Borohydride: An Ionic-Liquid-Based Hydrogen-Storage Material. Angew. Chem.-Int. Edit., 2010, 49 (10), 1871-1873.

[45] Bowden, M. E.; Brown, I. W. M.; Gainsford, G. J.; Wong, H. Structure and thermal decomposition of methylamine borane. Inorg. Chim. Acta, 2008, 361 (7), 2147-2153.

[46] Chua, Y. S.; Chen, P.; Wu, G. T.; Xiong, Z. T. Development of amidoboranes for hydrogen storage. Chem. Commun., 2011, 47 (18), 51165129.

[47] Zhao, Y: Deng, L.; Tang, S.-Y; Lai, D.-M.; Liao, B.; Fu, Y.; Guo, Q.-X. Selective Decomposition of Formic Acid over Immobilized Catalysts. Energy Fuels, 2011, 25 (8), 3693-3697.

[48] Boddien, A.; Mellmann, D.; Gartner, F.; Jackstell, R.; Junge, H.; Dyson, P. J.; Laurenczy, G.; Ludwig, R.; Beller, M. Efficient Dehydrogenation of Formic Acid Using an Iron Catalyst. Science, 2011, 333 (6050), 1733-1736.

[49] Tedsree, K.; Li, T.; Jones, S.; Chan, C. W. A.; Yu, K. M. K.; Bagot, P. A. J.; Marquis, E. A.; Smith, G. D. W.; Tsang, S. C. E. Hydrogen production from formic acid decomposition at room temperature using a Ag-Pd core-shell nanocatalyst. Nat. Nanotechnol., 2011, 6 (5), 302-307.

[50] Yasaka, Y.; Wakai, C.; Matubayasi, N.; Nakahara, M. Controlling the Equilibrium of Formic Acid with Hydrogen and Carbon Dioxide Using Ionic Liquid. J. Phys. Chem. A, 2010, 114 (10), 3510-3515.

[51] Johnson, T. C.; Morris, D. J.; Wills, M. Hydrogen generation from formic acid and alcohols using homogeneous catalysts. Chem. Soc. Rev., 2010, 39 (1), 81-88.

[52] Enthaler, S.; von Langermann, J.; Schmidt, T. Carbon dioxide and formic acid-the couple for environmental-friendly hydrogen storage? Energ. Environ. Sci., 2010, 3 (9), 1207-1217.
[53] Bulushev, D. A. Ross, J. R. H. Vapour phase hydrogenation of olefins by formic acid over a Pd/C catalyst. Catal. Today, 2011, 163 (1), 42-46.

[54] Kawasaki, I.; Tsunoda, K.; Tsuji, T.; Yamaguchi, T.; Shibuta, H.; Uchida, N.; Yamashita, M.; Ohta, S. A recyclable catalyst for asymmetric transfer hydrogenation with a formic acid-triethylamine mixture in ionic liquid. Chem. Commun., 2005, (16), 2134-2136.

[55] Blum, J; Sasson, Y; Iflah, S. Hydrogen transfer from formyl compounds to $\alpha, \beta$-unsaturated ketones catalyzed by $\mathrm{Ru}, \mathrm{Rh}$ and $\mathrm{Ir}$ complexes. Tetrahedron Lett., 1972, 13 (11), 1015-1018.

[56] Leitner, W.; Brown, J. M.; Brunner, H. Mechanistic Aspects of the RhodiumCatalyzed Enantioselective Transfer Hydrogenation of Alpha,BetaUnsaturated Carboxylic-Acids Using Formic-Acid Triethylamine (5-2) as the Hydrogen Source. J. Am. Chem. Soc., 1993, 115 (1), 152-159.

[57] Mateus, N. M. M. Branco, L. C.; Lourenco, N. M. T.; Afonso, C. A. M. Synthesis and properties of tetra-alkyl-dimethylguanidinium salts as a potential new generation of ionic liquids. Green Chem., 2003, 5 (3), 347-352.

[58] Stracke, M. P.; Ebeling, G.; Cataluna, R.; Dupont, J. Hydrogen-storage materials based on imidazolium ionic liquids. Energy Fuels, 2007, 21 (3), $1695-1698$.

[59] Zahmakiran, M.; Ozkar, S. Dimethylammonium Hexanoate Stabilized Rhodium(0) Nanoclusters Identified as True Heterogeneous Catalysts with the Highest Observed Activity in the Dehydrogenation of DimethylamineBorane. Inorg. Chem., 2009, 48 (18), 8955-8964.

[60] Himmelberger, D. W.; Alden, L. R.; Bluhm, M. E.; Sneddon, L. G. Ammonia Borane Hydrogen Release in Ionic Liquids. Inorg. Chem., 2009, 48 (20), 9883-9889

[61] Alcaraz, G.; Sabo-Etienne, S. Coordination and Dehydrogenation of AmineBoranes at Metal Centers. Angew. Chem.-Int. Ed., 2010, 49 (40), 7170-7179.

[62] Olivier-Bourbigou, H.; Magna, L.; Morvan, D. Ionic liquids and catalysis: Recent progress from knowledge to applications. Appl. Cat. A.-Gen., 2010, $373(1-2), 1-56$

[63] Taccardi, N.; Assenbaum, D.; Berger, M. E. M.; Bosmann, A.; Enzenberger, F.; Wolfel, R.; Neuendorf, S.; Goeke, V.; Schodel, N.; Maass, H. J.; Kistenmacher, H.; Wasserscheid, P. Catalytic production of hydrogen from glucose and other carbohydrates under exceptionally mild reaction conditions. Green Chem., 2010, 12 (7), 1150-1156. 